\title{
Antibacterial activity of amphiphilic tobramycin
}

\author{
Ramesh Dhondikubeer ${ }^{1}$, Smritilekha Bera ${ }^{1}$, George G Zhanel ${ }^{2}$ and Frank Schweizer ${ }^{1,2}$ \\ Amphiphilic aminoglycoside antimicrobials are an emerging class of new antibacterial agents with novel modes of action. \\ Previous studies have shown that amphiphilic neomycin-B and kanamycin-A analogs restore potent antibacterial activity against \\ Gram-positive neomycin-B- and kanamycin-A-resistant organisms. In this paper, we investigated the antibacterial properties of a \\ series of amphiphilic tobramycin analogs. We prepared tobramycin-lipid conjugates, as well as tobramycin-peptide triazole \\ conjugates, and studied their antibacterial activities against a panel of Gram-positive and Gram-negative bacterial strains, \\ including isolates obtained from Canadian hospitals. Our results demonstrate that the antibacterial activity of amphiphilic \\ tobramycin is greatly affected by the length and nature of the hydrophobic lipid tail, whereas the nature of the polycationic \\ headgroup or the number of cationic charges appear to be less important. Replacement of the hydrophobic tail by a fluorinated \\ lipid confers good activity against two Pseudomonas strains and reduces hemolytic activity. However, susceptibility studies in \\ the presence of bovine serum albumin indicate that all amphiphilic tobramycin analogs are strongly protein-bound, leading to a \\ typical four- to eight-fold increase in MIC.
}

The Journal of Antibiotics (2012) 65, 495-498; doi:10.1038/ja.2012.59; published online 11 July 2012

Keywords: aminoglycosides; antibacterial peptides; cationic amphiphiles; polycationic lipids

\section{INTRODUCTION}

Polycationic antibacterials (PAs) containing multiple positively charged amino and/or guanidino functions define a structurally diverse class of antibacterials with broad-spectrum activity and different modes of action. ${ }^{1}$ PAs can be divided into amphiphilic and non-amphiphilic PAs. Amphiphilic PAs are comprised of the naturally occurring cationic antimicrobial peptides, synthetic mimics of antimicrobial peptides, polycationic lipopeptides, lipids and surfactants, whereas non-amphiphilic PAs are represented by aminoglycoside antibiotics. The polycationic charges in PAs ensure accumulation at polyanionic microbial cell surfaces in Gramnegative and Gram-positive bacteria, respectively. ${ }^{2}$ Several PAs including the aminoglycoside gentamicin, certain antimicrobial peptides including defensins, gramicidin $\mathrm{S}$ variants and others, and lipopeptides such as polymyxins transit the outer membrane by interacting at sites at which divalent cations crossbridge adjacent polyanionic polymers. This causes a destabilization of the outer membrane that is proposed to lead to self-promoted uptake of PAs and/or other extracellular molecules. ${ }^{2}$ After transit through the outer membrane, PAs contact the anionic surface of the cytoplasmic membrane. Here, depending on the structure of the Pas, several scenarios can be envisaged. Amphiphilic PAs may insert themselves into the cytoplasmic membrane, thereby either disrupting the physical integrity of the bilayer, via membrane thinning, transient poration and/or disruption of the barrier function, or translocation across the membrane and acting on internal targets. ${ }^{2}$ Non-amphiphilic PAs like aminoglycosides must cross the membrane to bind to ribosomal RNA.
Our previous work has shown that amphiphilic aminoglycosides such as neomycin, kanamycin and neamine analogs restore potent antibacterial activities against certain Gram-positive and Gramnegative organisms, including multidrug-resistant isolates obtained from Canadian hospitals. ${ }^{3-7}$ For instance, when compared with their parent aminoglycosides, both neomycin-B-based hexacationic $\mathrm{C}_{16^{-}}$ lipid 7 or kanamycin-A-based tetracationic lipid $\mathrm{C}_{16}$-lipid 6 (Figure 1) displayed 64- to 32-fold enhanced antibacterial activity against methicillin-resistant Staphylococcus aureus, whereas a 4- to 8-fold decrease in MIC was observed against two Pseudomonas aeruginosa strains. ${ }^{4}$ Similarly, conjugation of neomycin-B and kanamycin-A to an ultrashort hydrophobic dipeptide led to a 16-fold lower MIC against methicillin-resistant Staphylococcus aureus and a 4- to 32-fold lower MIC against Pseudomonas aeruginosa strains. The physicochemical similarities between amphiphilic aminoglycosides and amphiphilic PAs suggest a membranolytic mode of action. ${ }^{8,9}$ This hypothesis is supported by (a) the observed concentration-dependent hemolytic activity of 6 and $7 ;^{5}$ and (b) the requirement for a strongly hydrophobic lipid segment to induce potent antibacterial activity ${ }^{4}$ and a recent study of C5"-modified neomycin-B-based polycationic lipids that have demonstrated that polycationic neomycin-lipid conjugates synergistically enhance the antibacterial activity of antibiotics interacting with intracellular targets such as amikacin and neomycin. ${ }^{9}$ To further explore the structural activity relationships in this class of polycationic amphiphiles, we now became interested in studying the antibacterial effects of amphiphilic tobramycin analogs. To the best of our knowledge, this is the first study on amphiphilic 
tobramycin analogs. We were particularly interested in exploring how the nature of the hydrophobic lipid tail affects antibacterial activity in amphiphilic tobramycin analogs, and how the activity of amphiphilic tobramycin compares with amphiphilic kanamycin-A and neomycin-B.

\section{MATERIALS AND METHODS}

\section{Antibacterial agents}

Two classes of amphiphilic tobramycin analogs were prepared. The first class are tobramycin-based polycationic lipids 2, 3, 4 and $\mathbf{5}$ (Figure 1), whereas the second class are tobramycin-based triazole conjugates $\mathbf{9}$ and $\mathbf{1 0}$ (Figure 2). We also studied the corresponding kanamycin-A- and neomycin-B-based polycationic lipids 6, 7 and 8, together with their triazole conjugates 11 and 12 . Tobramycin, kanamycin, neomycin and 6'-azidodeoxy-tobramycin $\mathbf{1}$ served as reference compounds. All synthetic compounds were prepared following our previously established methodology., ${ }^{3,4,6}$ The identity of all amphiphilic tobramycin, neomycin-B and kanamycin-A analogs were assessed by EI-MS, ${ }^{1} \mathrm{H}$ NMR, and ${ }^{13} \mathrm{C}$ NMR (see Supplementary Information). Tobramycin, kanamycin-A and neomycin-B were purchased from Sigma Aldrich Canada Ltd (Oakville, Ontario, Canada)

\section{Bacterial strains}

American Type Culture Collection (ATCC) strains as well as clinical isolates from the Canadian Intensive Care Unit (CAN-ICU) study were used, including Staphylococcus aureus ATCC 29213, methicillin-resistant Staphylococcus aureus

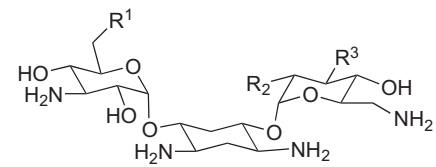

tobramycin: $\mathrm{R}^{1}=\mathrm{OH} ; \mathrm{R}^{2}=\mathrm{NH}_{2} ; \mathrm{R}^{3}=\mathrm{H}$ 1: $\mathrm{R}^{1}=\mathrm{N}_{3} ; \mathrm{R}^{2}=\mathrm{NH}_{2} ; \mathrm{R}^{3}=\mathrm{H}$ 2: $\mathrm{R}^{1}=\mathrm{OC}(\mathrm{O}) \mathrm{NHC}_{6} \mathrm{H}_{13} ; \mathrm{R}^{2}=\mathrm{NH}_{2} ; \mathrm{R}^{3}=\mathrm{H}$ 3: $\mathrm{R}^{1}=\mathrm{OC}(\mathrm{O}) \mathrm{NHC}_{6} \mathrm{H}_{5} ; \mathrm{R}^{2}=\mathrm{NH}_{2} ; \mathrm{R}^{3}=\mathrm{H}$ 4: $\mathrm{R}^{1}=\mathrm{NHCOC}_{15} \mathrm{H}_{31} ; \mathrm{R}^{2}=\mathrm{NH}_{2} ; \mathrm{R}^{3}=\mathrm{H}$ 5: $\mathrm{R}^{1}=\mathrm{NHCOC}_{2} \mathrm{H}_{4} \mathrm{C}_{8} \mathrm{~F}_{17} ; \mathrm{R}^{2}=\mathrm{NH}_{2} ; \mathrm{R}^{3}=\mathrm{H}$ kanamycin $\mathrm{A}: \mathrm{R}^{1}=\mathrm{OH} ; \mathrm{R}^{2}=\mathrm{OH} ; \mathrm{R}^{3}=\mathrm{OH}$ 6: $\mathrm{R}^{1}=\mathrm{NHCOC}_{15} \mathrm{H}_{31} ; \mathrm{R}^{2}=\mathrm{OH} ; \mathrm{R}^{3}=\mathrm{OH}$

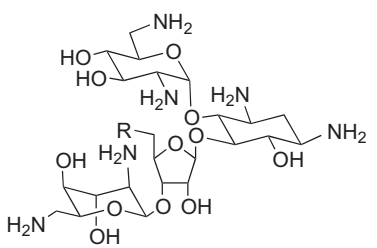

neomycin $\mathrm{B}: \mathrm{R}=\mathrm{OH}$ 7: $\mathrm{R}=\mathrm{NHCOC}{ }_{15} \mathrm{H}_{3}$ 8: $\mathrm{R}=\mathrm{NHCOC}_{2} \mathrm{H}_{4} \mathrm{C}_{8} \mathrm{~F}_{17}$

Figure 1 Structures of amphiphilic tobramycin-, kanamycin-A- and neomycin-B-based polycationic lipids.
ATCC 33592, Staphylococcus epidermidis ATCC 14990, methicillin-resistant Staphylococcus epidermidis (Cefazolin-CZ MIC $>32 \mu \mathrm{g} \mathrm{ml}^{-1}$ ) CAN-ICU 61589, Enterococcus faecalis ATCC 29212, Enterococcus faecium ATCC 27270 Streptococcus pneumoniae ATCC 49619, Escherichia coli ATCC 25922, E. coli ATCC (Gentamicin resistant) CAN-ICU 61714, E. coli ATCC (Amikacin MIC $32 \mathrm{\mu g} \mathrm{ml}^{-1}$ ) CAN-ICU 63074, Pseudomonas aeruginosa ATCC 27853, Pseudomonas aeruginosa (Gentamicin resistant) CAN-ICU 62308, Stenotrophomonas maltophilia CAN-ICU 62584, Acinetobacter baumannii CAN-ICU 63169 and Klebsiella pneumoniae ATCC $13883 .^{10}$

\section{MIC determination}

Antibacterial activity against Gram-positive and Gram-negative organisms was assessed via broth macrodilution using Clinical and Laboratory Standards Institute (CLSI) methodology. ${ }^{10}$ Stock solutions of amphiphilic aminoglycosides were prepared to a concentration of $512 \mu \mathrm{g} \mathrm{ml}^{-1}$ in water. Organisms were subcultured and isolated on blood agar, suspended in $3 \mathrm{ml}$ of Mueller-Hinton broth at the turbidity of a $0.5 \mathrm{M}$ McFarland standard, and diluted to approximately $10^{5} \mathrm{CFU} \mathrm{ml}^{-1}$ before introduction into tubes containing serially diluted lipopeptide antibiotic in Mueller-Hinton broth The turbidity resulting from lipopeptide solution in broth required the creation of control tubes lacking microbes serving as turbidity controls. All tubes were incubated overnight for $16-20 \mathrm{~h}$ at $37^{\circ} \mathrm{C}$. In some cases, the MIC study was performed in the presence of $4 \%$ bovine serum albumin to study protein binding.

\section{Hemolytic activity}

In-vitro toxicity was determined using a sheep red blood cell hemolytic assay as previously described. ${ }^{11}$ Pilot experiments have shown that both human and sheep erythrocytes respond similarly in this hemolytic assay (data not shown). In brief, the erythrocytes were washed and resuspended in Tris-buffered saline. The cell suspension will be combined with varying concentrations (low to very high) of kanamycin, neomycin, tobramycin and amphiphilic aminoglycosides. The samples were centrifuged and the absorbance of the supernatants was measured at $540 \mathrm{~nm}$. Tris-buffered saline and Triton X were used as negative and positive controls, respectively. The toxicity was assessed by percent hemolysis. ${ }^{11}$

\section{RESULTS AND DISCUSSION}

In this study, a total of seven amphiphilic and non-amphiphilic tobramycin-based analogs as well as certain corresponding amphiphilic kanamycin and neomycin analogs were synthesized. Our curiosity was driven by previous observations from our laboratory ${ }^{3-5}$
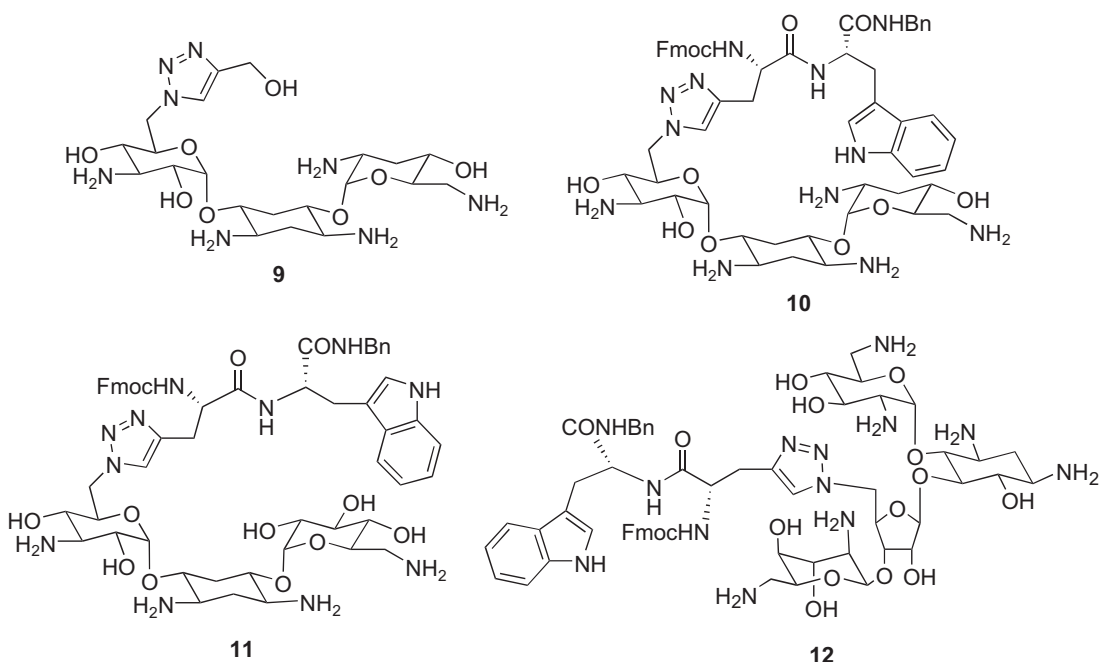

Figure 2 Structures of amphiphilic tobramycin-, kanamycin-A- and neomycin-B-based triazole peptide conjugates. 
and others, ${ }^{7,8}$ which have shown that conversion of the nonamphiphilic aminoglycosides neomycin-B and kanamycin-A into amphiphilic aminoglycosides enhances antibacterial activity against aminoglycoside-resistant and multidrug-resistant Gram-positive bacteria. $^{3-5}$ The compounds were selected to explore how the nature of the cationic aminoglycoside-based headgroup, the number of cationic charges and the nature of the hydrophobic lipid tail affects antibacterial activity in this class of compounds. At first, we explored how the nature of the hydrophobic tail affects the antibacterial activity in tobramycin-based amphiphiles. The single primary hydroxy group of tobramycin was converted into an amino function and conjugated to various fatty acid-based lipid tails. We selected a $\mathrm{C}_{16^{-}}$and fluorinated $\mathrm{C}_{12}$-lipid tails. We also explored aromatic tails and shorter $\mathrm{C}_{6}$ lipid tails in the form of carbamates. Our results clearly demonstrate that amphiphilicity is critical for antibacterial activity as tobramycin- $\mathrm{C}_{6}$ lipid 2 and tobramycin-phenylcarbamate $\mathbf{3}$ are nearly devoid of antibacterial activity (Table 1 ). In contrast, tobramycin- $\mathrm{C}_{16^{-}}$ lipid 4 displays good antibacterial activity against most Gram-positive (MIC $\leqslant 4-8 \mu \mathrm{g} \mathrm{ml}^{-1}$ ), and some Gram-negative organisms including E. coli and one Pseudomonas aeruginosa strain. The potent activity of 4 (MIC <0.25) against methicillin-resistant Staphylococcus epidermidis is especially noteworthy. Replacement of the $\mathrm{C}_{16}$-lipid in 4 by a partially fluorinated lipid tail with comparable hydrophobicity ${ }^{12}$ as in compound $\mathbf{5}$ does not improve the antibacterial activity and generally leads to an expected two-fold reduction in MIC when the increase in MW is considered. It is noteworthy that compound $\mathbf{5}$ displays good antibacterial activity $(\mathrm{MIC}=16)$ against two Pseudomonas aeruginosa strains.

Next, we studied how the nature of the polycationic headgroup and the number of polycationic charges affects the antibacterial activity. Besides the pentacationic tobramycin-based headgroup, we selected the tetracationic kanamycin-A and the hexacationic neomycin-B headgroups. With the exception of methicillin-resistant Staphylococcus epidermidis and Pseudomonas aeruginosa, conjugation of the three differently charged headgroups to a $\mathrm{C}_{16}$ hydrophobic tail results in almost identical antibacterial activity for compounds 4, 6 and 7, indicating that the nature of the polycationic headgroup is not critical for the antibacterial activity. Interestingly, a four- to eight-fold reduction in MIC is observed against Pseudomonas aeruginosa and methicillin-resistant Staphylococcus epidermidis when the polycationic headgroup of neomycin and kanamycin is replaced by tobramycin, indicating that the pentacationic tobramycin-based headgroup appears to be optimal for both organisms. In addition, as observed for tobramycin analog

Table 1 Antibacteral activities (MIC $\mu \mathrm{g} \mathrm{ml}^{-1}$ ) of amphiphilic aminoglycoside antimicrobals

\begin{tabular}{|c|c|c|c|c|c|c|c|c|c|c|c|c|c|c|c|}
\hline Control organism & Tobramycin & 1 & 2 & 3 & 4 & 5 & 9 & 10 & Kanamycin & 6 & 11 & Neomycin & 7 & 8 & 12 \\
\hline $\begin{array}{l}\text { Staphylococcus aureus } \\
\text { ATCC29213 }\end{array}$ & $0.5(0.5)$ & $8(4)$ & 256 & 256 & $8(32)$ & $16(64)$ & $2(2)$ & $8(16)$ & 4 & 8 & 16 & 1 & 4 & 16 & 8 \\
\hline MRSA ATCC33592 & $0.5(1)$ & $8(4)$ & 512 & 512 & $8(64)$ & $\begin{array}{c}32 \\
(256)\end{array}$ & $\begin{array}{c}64 \\
(128)\end{array}$ & $16(32)$ & $>512$ & 16 & 32 & 256 & 8 & 64 & 16 \\
\hline $\begin{array}{l}\text { Staphylococcus epidermi- } \\
\text { dis ATCC } 14990\end{array}$ & $\begin{array}{l}\leqslant 0.25 \\
(\leqslant 0.25)\end{array}$ & $8(4)$ & 128 & 64 & $4(32)$ & $8(64)$ & $1(2)$ & $8(16)$ & 2 & 2 & 8 & 0.25 & 2 & 8 & 4 \\
\hline MRSE CAN-ICU 61589 & $2(2)$ & $4(16)$ & 128 & 256 & $\begin{array}{l}<0.25 \\
(32)\end{array}$ & $\begin{aligned} \leqslant & 0.25 \\
& (64)\end{aligned}$ & $16(64)$ & $16(64)$ & 128 & 2 & 16 & 0.5 & 2 & 4 & 8 \\
\hline $\begin{array}{l}\text { Enterococcus faecalis } \\
\text { ATCC } 29212\end{array}$ & $8(16)$ & $16(16)$ & 256 & 256 & $8(64)$ & $\begin{array}{c}16 \\
(512)\end{array}$ & $64(64)$ & $32(64)$ & n.d. & 8 & n.d. & n.d. & n.d. & 64 & n.d. \\
\hline $\begin{array}{l}\text { Enterococcus faecium } \\
\text { ATCC } 27270\end{array}$ & $16(8)$ & $\begin{array}{c}128 \\
(128)\end{array}$ & 256 & 512 & $4(32)$ & $0.5(64)$ & $\begin{array}{c}128 \\
(128)\end{array}$ & $16(64)$ & n.d. & 8 & n.d. & n.d. & n.d. & 32 & n.d. \\
\hline $\begin{array}{l}\text { Streptococcus pneumoniae } \\
\text { ATCC49619 }\end{array}$ & $2(2)$ & $2(1)$ & 512 & 256 & $\begin{array}{l}128 \\
(512)\end{array}$ & $\begin{array}{l}128 \\
(512)\end{array}$ & $16(16)$ & $\begin{array}{c}64 \\
(128)\end{array}$ & 8 & 64 & 64 & 32 & 64 & 64 & 64 \\
\hline $\begin{array}{l}\text { Escherichia coli } \\
\text { ATCC25922 }\end{array}$ & $0.5(0.5)$ & $8(4)$ & $\begin{array}{c}64 \\
(128)\end{array}$ & $8(8)$ & $\begin{array}{c}32 \\
(128)\end{array}$ & $\begin{array}{c}64 \\
(256)\end{array}$ & $4(8)$ & $16(8)$ & 8 & 32 & 32 & 4 & 32 & 32 & 16 \\
\hline $\begin{array}{l}\text { Escherichia coli CAN-ICU } \\
61714\end{array}$ & $8(8)$ & 32 (32) & $>512$ & 512 & $\begin{array}{c}32 \\
(128)\end{array}$ & $\begin{array}{c}64 \\
(512)\end{array}$ & $\begin{array}{c}256 \\
(256)\end{array}$ & $\begin{array}{c}32 \\
(256)\end{array}$ & 16 & 32 & 32 & 8 & 64 & 32 & 32 \\
\hline $\begin{array}{l}\text { Escherichia coli CAN-ICU } \\
63074\end{array}$ & $8(8)$ & $8(8)$ & $\begin{array}{c}128 \\
(256)\end{array}$ & $\begin{array}{l}32 \\
(64)\end{array}$ & $8(64)$ & $\begin{array}{c}64 \\
(512)\end{array}$ & $64(64)$ & $\begin{array}{c}32 \\
(128)\end{array}$ & 32 & 32 & 32 & n.d. & n.d. & 64 & n.d. \\
\hline $\begin{array}{l}\text { Pseudomonas aeruginosa } \\
\text { ATCC } 27853\end{array}$ & $0.5(0.5)$ & $4(4)$ & $>512$ & 512 & $\begin{array}{c}128 \\
(256)\end{array}$ & $16(64)$ & 8 (16) & $\begin{array}{c}32 \\
(128)\end{array}$ & $>512$ & 64 & 128 & 512 & 128 & 128 & 128 \\
\hline $\begin{array}{l}\text { Pseudomonas aeruginosa } \\
\text { CAN-ICU } 62308\end{array}$ & $16(32)$ & $\begin{array}{c}128 \\
(256)\end{array}$ & $>512$ & 512 & $16(64)$ & $16(64)$ & $\begin{array}{c}256 \\
(512)\end{array}$ & $16(64)$ & $>512$ & 64 & 16 & 512 & 128 & 32 & 64 \\
\hline $\begin{array}{l}\text { Stenotrophomonas } \\
\text { maltophilia CAN-ICU } \\
62584\end{array}$ & $\begin{array}{l}>512 \\
(>512)\end{array}$ & $\begin{array}{l}>512 \\
>512\end{array}$ & $>512$ & $>512$ & $\begin{array}{c}256 \\
(512)\end{array}$ & $\begin{array}{l}>512 \\
(>512)\end{array}$ & $\begin{array}{l}>512 \\
(>512)\end{array}$ & $\begin{array}{c}256 \\
(>512)\end{array}$ & $>512$ & $<128$ & n.d. & $>512$ & n.d. & $>512$ & n.d. \\
\hline $\begin{array}{l}\text { Acinetobacter baumannii } \\
\text { CAN-ICU } 63169\end{array}$ & $16(8)$ & $\begin{array}{c}256 \\
(128)\end{array}$ & $>512$ & $>512$ & $\begin{array}{l}256 \\
(512)\end{array}$ & $\begin{array}{c}512 \\
(>512)\end{array}$ & $\begin{array}{c}512 \\
(>512)\end{array}$ & $\begin{array}{c}256 \\
(512)\end{array}$ & 16 & $<128$ & n.d. & 32 & n.d. & 512 & n.d. \\
\hline $\begin{array}{l}\text { Streptococcus pneumoniae } \\
\text { ATCC } 13883\end{array}$ & $\begin{array}{l}>0.25 \\
(>0.25)\end{array}$ & $16(8)$ & 128 & $4(4)$ & $\begin{array}{c}32 \\
(128)\end{array}$ & $\begin{array}{c}128 \\
(256)\end{array}$ & $2(2)$ & $\begin{array}{l}256 \\
(512)\end{array}$ & 0.5 & 16 & n.d. & $\leqslant 0.25$ & n.d. & 512 & n.d. \\
\hline $\begin{array}{l}\% \text { Hemolytic activity at } \\
\left(100 \text { or } 500 \mu \mathrm{g} \mathrm{ml}^{-1} \text { ) }\right.\end{array}$ & $\begin{array}{c}<0.5 \\
(<0.5)\end{array}$ & $\begin{array}{c}1.2 \\
(1.7)\end{array}$ & $\begin{array}{c}0.8 \\
(1.0)\end{array}$ & $\begin{array}{c}1.5 \\
(1.6)\end{array}$ & $\begin{array}{l}37 \% \\
(100)\end{array}$ & $\begin{array}{c}1.3 \\
(27.1)\end{array}$ & $\begin{array}{c}0.8 \\
(0.7)\end{array}$ & $\begin{array}{c}12.4 \\
(56.5)\end{array}$ & $\begin{array}{c}<0.5 \\
(<0.5)\end{array}$ & $\begin{array}{c}20 \\
\text { (n.d.) }\end{array}$ & $\begin{array}{l}3.9 \\
\text { (n.d.) }\end{array}$ & $\begin{array}{c}<0.5 \\
(<0.5)\end{array}$ & $\begin{array}{c}56 \\
\text { (n.d.) }\end{array}$ & $\begin{array}{c}1.1 \\
(9.4)\end{array}$ & $\begin{array}{l}9.9 \\
\text { (n.d.) }\end{array}$ \\
\hline
\end{tabular}

Abbreviations: ATCC, American Type Culture Collection; BSA, bovine serum albumin; CAN-ICU, Canadian Intensive Care Unit; MRSA, methicillin-resistant Staphylococcus aureus; MRSE, methicillin-resistant Staphylococcus epidermidis; n.d., not defined.

Values in brackets were determined in the presence of $4 \%$ BSA. 
5, replacement of the hydrophobic tail by a fluorinated lipid tail does not enhance antibacterial activity.

We also studied how substitution of the fatty acid-based lipid tail by a hydrophobic dipeptide sequence affects antibacterial activity in amphiphilic tobramycin analog 10 (Figure 2). For comparison with previously synthesized amphiphilic peptides 11 and 12, we selected the hydrophobic Fmoc-protected dipeptide sequence consisting of triazol-modified glycine and tryptophan. ${ }^{6}$ A previous study has shown that the hydrophobic Fmoc-protecting group in this dipeptide sequence improves antibacterial activity. ${ }^{6}$ We also prepared the less amphiphilic tobramycin-based triazole analog 9 as a reference compound. Our results demonstrate that replacement of the lipid tail in 4 by a hydrophobic peptide sequence in compound $\mathbf{1 0}$ results in a two- to four-fold increase in MIC against most Grampositive strains, whereas the same or a two-fold increased MIC was observed against most Gram-negative organisms. The same trend is observed with amphiphilic kanamycin-A peptide triazole conjugate 11 and neomycin-B triazole conjugate $\mathbf{1 2}$.

To further explore the potential toxicity of amphiphilic tobramycin analogs, we studied their hemolytic activities at two different concentrations (Table 1). Our results demonstrate that amphiphilic tobramycin analogs with highly hydrophobic tails such as compounds $\mathbf{4}$ and $\mathbf{1 0}$ show concentration-dependent hemolytic activity, as it is observed for other amphiphilic aminoglycoside analogs such as compounds 6 and 7. Generally, it appears that a hydrophobic peptide tail results in reduced hemolytic activity when compared with a $\mathrm{C}_{16}$ lipid tail for all three types of aminoglycosides. Moreover, replacement of the hydrophobic lipid tail in both compounds 4 and 7 by a fluorinated lipid tail as in compounds $\mathbf{5}$ and $\mathbf{8}$ significantly reduces the hemolytic activity, suggesting that fluorinated lipid tails may reduce cytotoxicity. However, both amphiphilic tobramycin-lipid conjugates experience a typical four- to eight-fold reduction in antibacterial activity against most organisms in the presence of $4 \%$ bovine serum albumin, indicating that these compounds bind strongly to proteins. A similar antibacterial deactivation has previously been observed with other classical cationic amphiphiles such as benzethonium chloride. ${ }^{13}$

In summary, we have established that the antibacterial activity of amphiphilic tobramycin analogs is greatly affected by the length and nature of the lipid tail. In contrast, the nature of the polycationic headgroup or the number of the cationic charges appear to be less important for induction of antibacterial activity. The most potent antibacterial is tobramycin- $\mathrm{C}_{16}$ lipid 4 , which displays good Gram- positive activity, but reduced Gram-negative activity. Replacement of the $\mathrm{C}_{16}$ lipid tail by a fluorinated lipid tail confers good activity against two Pseudomonas aeruginosa strains and reduces hemolytic activity. However, susceptibility studies in the presence of bovine serum albumin indicate that all amphiphilic tobramycin analogs are strongly protein-bound, leading to a typical four- to eight-fold increase in MIC.

\section{ACKNOWLEDGEMENTS}

We thank Nancy Liang for help in antibacterial susceptibility testing. This study was supported by the Natural Sciences and Engineering Research Council of Canada (NSERC), the Canadian Institutes of Health Research (CIHR), the Manitoba Health Research Council (MHRC) and the Canadian Foundation for Innovation (CFI).

1 Findlay, B., Zhanel, G. G. \& Schweizer, F. Cationic amphiphiles: a new generation of antimicrobials inspired by the natural antimicrobial peptide scaffold. Antimicrob. Agents Chemother. 54, 4049-4058 (2010).

2 Hancock, R. E. W. homepage http://cmdr.ubc.ca/bobh/uptake.html.

3 Bera, S., Zhanel, G. G. \& Schweizer, F. Antibacterial activities of aminoglycoside antibiotics-derived cationic amphiphiles. Polyol-modified neomycin B, kanamycin A, amikacin- and neamine-based amphiphiles with potent broad spectrum antibacterial activity. J. Med. Chem. 53, 3626-3631 (2010).

4 Bera, S., Zhanel, G. G. \& Schweizer, F. Design, synthesis and antibacterial activities of neomycin-lipid conjugates: polycationic lipids with potent Gram-positive activity. J. Med. Chem. 51, 6160-6164 (2008).

5 Bera, S., Zhanel, G. G. \& Schweizer, F. Antibacterial activity of guanidinylated neomycin B- and kanamycin A-derived amphiphilic lipid conjugates. J. Antimicrob. Chemother. 65, 1224-1227 (2010).

6 Bera, S., Zhanel, G. G. \& Schweizer, F. Evaluation of amphiphilic aminoglycosidepeptide triazole conjugates as antibacterial agents. Bioorg. Med. Chem. Lett. 20, 3031-3035 (2010)

7 Baussanne, I. et al. Synthesis and antimicrobial evaluation of amphiphilic neamine derivatives. J. Med. Chem. 53, 119-127 (2010).

8 Ouberai, M. et al. The Pseudomonas aeruginosa membranes: a target for a new amphiphilic aminoglycoside derivative? Biochim. Biophys. Acta 1808, 1716-1727 (2011)).

9 Zhang, J. et al. Synthesis and combinational studies of 5"-modified neomycin. J. Antibiot 44, 539-542 (2009).

10 Zhanel., G. G. et al. Antimicrobial resistant pathogens in intensive care units across Canada: results of the Canadian National Intensive Care Unit (CAN-ICU) Study 2005/ 2006. Antimicrob. Agents Chemother. 52, 1430-1437 (2008).

11 Dathe, M. et al. Peptide helicity and membrane surface charge modulate the balance of electrostatic and hydrophobic interactions with lipid bilayers and biological membranes. Biochemistry 35, 12612-12622 (1996).

$12 \mathrm{Li}, \mathrm{X}$. et al. Synthesis and biocompatibility evaluation of fluorinated, single-tailed glucopyranoside surfactants. New J. Chem. 32, 2169-2179 (2008).

13 Findlay, B., Zhanel, G. G. \& Schweizer, F. Neomycin-phenolic conjugates: polycationic amphiphiles with broad-spectrum antibacterial activity, low haemolytic activity and weak serum protein binding. Bioorg. Med. Chem. Lett. 22, 1499-1503 (2012)

Supplementary Information accompanies the paper on The Journal of Antibiotics website (http://www.nature.com/ja) 